\title{
COMPORTAMENTO DO SISTEMA RADICULAR DE CAPINS MANEJADOS POR PASTEJO SUBMETIDOS A DIFERENTES LÂMINAS DE IRRIGAÇÃO
}

Carlos Augusto Brasileiro de Alencar ${ }^{1}$, Rubens Alves de Oliveira², Antônio Carlos Cóser ${ }^{3}$, Carlos Eugênio Martins ${ }^{3}$, Fernando França da Cunha ${ }^{1}$

\section{RESUMO}

Objetivou-se com a realização deste trabalho, avaliar a densidade de raiz (DR) e profundidade efetiva do sistema radicular (PE) em seis capins manejados por pastejo sob efeito de diferentes lâminas de irrigação. O experimento foi conduzido em esquema de parcelas subdivididas, tendo nas parcelas seis gramíneas (Xaraés, Mombaça, Tanzânia, Pioneiro, Marandu e Estrela) e nas subparcelas três lâminas de irrigação (0, 45 e 100\% da referência) no delineamento inteiramente casualizado, com duas repetições. Para diferenciar a aplicação das lâminas de irrigação, utilizou-se o sistema por aspersão em linha. A densidade de raiz foi obtida pela densidade média de todas as amostras e a profundidade efetiva onde se concentravam $80 \%$ de massa das raízes. Observou-se que os capins não apresentaram diferença na DR nos tratamentos não irrigados. Nos tratamentos de 45 e 100\% da referência observou-se que os capins Xaraés e Marandu apresentaram maiores DR. O aumento da lâmina de irrigação aumentou a DR apenas dos capins Xaraés e Marandu. Não foi observado efeito estatístico dos capins e das lâminas de irrigação na PE, porém o capim-marandu se destacou por apresentar maior média.

Palavras-chave: B. brizantha, C. nlemfuensis, P. maximum, P. purpureum, profundidade efetiva, densidade de raiz.

\section{BEHAVIOR OF THE ROOT SYSTEM OF THE GRAZE MANAGED GRASSES UNDER DIFFERENT IRRIGATION DEPTHS}

\begin{abstract}
This study was done to evaluate the root density and root depth of six pasture grasses irrigated with different water depths. The experiment was conducted in a completely randomized split plot design, with two replications. The grasses (Xaraes, Mombaça, Tanzania, Pioneiro, Marandu and Estrela) constituted the plots and water depths (0, 45 and 100\% of the reference) the split-plots. Irrigation was done with the use of a line source sprinkler system. The root density was evaluated by the calculating the mean density of all samples and the effective root depth was represented by the depth where $80 \%$ of the root weight was concentrated. In non-irrigated plots root density did not differ among grasses, but Xaraes and Marandu had higher root density irrigated to 45 or 100\% of the reference. Increasing water depth increased root density of only Xaraes and Marandu. The effect of water depth on effective root depth did not differ among grasses, although the mean values of Marandu was higher.
\end{abstract}

Keywords: B. brizantha, C. nlemfuensis, P. maximum, P. purpureum, root depth, root density.

\section{Recebido para publicação em 01/02/2008. Aprovado em 15/03/2010}

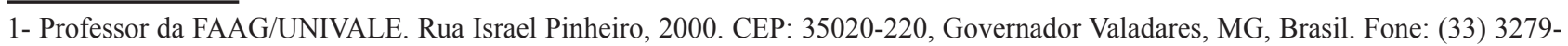
5995. E-mail: c.brasileiro@yahoo.com.br, cunhaff@yahoo.com.br

2- Professor do DEA/UFV. Av. Peter Henry Rolfs, s/n, CEP: 36570-000, Viçosa, MG. Fone: (31) 3899-1909. E-mail: rubens@ufv.br 3-Pesquisador do CNPGL/EMBRAPA. Rua Eugênio do Nascimento, 610. CEP: 36038-330, Juiz de Fora, MG. Fone: (32) 3249-4870. E-mail: acoser@cnpgl.embrapa.br, caeuma@cnpgl.embrapa.br 
INTRODUÇÃO

As pastagens, por seu baixo custo de produção em relação ao dos concentrados, representam a forma mais prática e econômica de alimentação de bovinos (FERNANDES et al., 2003). Diante disso, grande parte da carne e do leite produzidos no País advém de rebanhos mantidos a pasto.

O processo de intensificação da produção de leite e de carne bovina implica em uso de forrageiras com alta capacidade de produção de matéria seca, destacando-se os cultivares dos gêneros Pennisetum, Cynodon, Panicum e Brachiaria, por causa de seu elevado potencial produtivo e de sua qualidade. A região Leste do Estado de Minas Gerais apresenta grande potencial para o uso dessas forrageiras. Entretanto, informações disponíveis sobre essas gramíneas são ainda pouco conhecidas.

O desenvolvimento do sistema radicular das plantas cultivadas vem sendo abordado nos estudos das inter-relações entre solo e planta, mas esses estudos ainda são escassos, face a todas as culturas, inclusive as forrageiras. e a quantificação de raízes usualmente envolver a utilização de métodos complexos e dispendiosos. A formação de um sistema radicular vigoroso é fundamental para que as plantas suportem situações de estresse, como invernos rigorosos, verões secos e o próprio pastejo. Dada a importância do sistema radicular das pastagens, Scheffer-Basso et al. (2002) defendem a inclusão desta característica agronômica na seleção de genótipos superiores em qualquer espécie forrageira. Segundo Volaire et al. (1998), essas características foram consideradas, na seleção de cultivares de azevém (Lolium rigidum).

De acordo com Cecato et al. (2001), o sistema radicular das plantas forrageiras é afetado diretamente pelas condições físicas do solo, nutrientes, umidade, dentre outros. O manejo de forrageiras por pastejo pode interferir diretamente nas propriedades físicas do solo e indiretamente no desenvolvimento do sistema radicular. Um exemplo é a redução do percentual de macroporos e aumento da densidade do solo, quando esse é submetido ao pisoteio animal. Também quando da remoção da parte aérea, por meio do corte ou pastejo de forma muito intensa e frequente, há declínio da produção das plantas (CORSI \& NASCIMENTO Jr., 1994; CECATO et al., 2001 e SCHEFFER-BASSO et al., 2002). Primeiro, ocorre prejuízo nas raízes e, posteriormente, na parte aérea (CECATO et al., 2001).
As irregularidades do regime pluvial tornamse uma restrição ao desenvolvimento de plantas forrageiras, pois, mesmo dentro de estações chuvosas, observam-se períodos de déficit hídrico, pois a evapotranspiração da pastagem geralmente excede a precipitação pluvial. O manejo da irrigação é um recurso para racionalizar a aplicação de água às culturas, de maneira complementar às precipitações pluviais, necessitando-se de procedimentos técnicos para determinar o turno de rega e a quantidade de água a aplicar (RASSINI, 2001). Assim, a reposição de água ao solo, por meio da irrigação, na quantidade adequada e no momento oportuno, é decisiva para o sucesso da intensificação da produção.

O nível de umidade do solo pode influenciar o efeito da fertilidade no comportamento do sistema radicular. Giacomini et al. (2005) avaliando o crescimento de raízes dos capins Aruana (Panicum maximum Jacq. cv. Aruana) e Tanzânia (Panicum maximum Jacq. cv. Tanzânia), submetidos a doses de nitrogênio de 150 e $300 \mathrm{~kg} \mathrm{ha}^{-1}$, observaram que a adubação nitrogenada influenciou $\mathrm{o}$ crescimento de raízes nos períodos em que houve maior pluviosidade, de modo que a menor dose de nitrogênio promoveu maior crescimento de raízes. Doorenbos \& Pruitt (1977), estudando a absorção de água no perfil do solo, concluíram que a maioria das plantas retira $40 \%$ do total de água utilizada do quarto superior do perfil do solo, abrangido pelo sistema radicular, e 30, 20 e $10 \%$ da segunda, terceira e quarta frações do perfil do solo explorado pelas raízes, respectivamente. Hunt et al. (1998) relataram que a distribuição do sistema radicular no solo não é uniforme, sendo o movimento de água maior nas regiões do perfil onde as raízes estão mais concentradas. Nesses locais, a depleção do teor de água no solo é bem mais rápida.

Objetivou-se, com este trabalho, estudar a densidade e profundidade efetiva do sistema radicular de capins cultivados por pastejo, sob efeito de diferentes lâminas de irrigação, na região Leste de Minas Gerais.

\section{MATERIAL E MÉTODOS}

O experimento foi conduzido em maio de 2003 a abril de 2005, na Universidade Vale do Rio Doce, localizada no município de Governador Valadares, MG, sendo as coordenadas geográficas $18^{\circ} 47^{\prime} 30^{\prime \prime}$ de latitude sul e $41^{\circ} 59^{\prime} 04^{\prime}$ 'de longitude oeste e altitude de $223 \mathrm{~m}$. 
As médias de precipitação e de evapotranspiração potencial de referência durante os dois anos de experimento foram de $1064 \mathrm{~mm} \mathrm{e} 1277 \mathrm{~mm}$, respectivamente. $\mathrm{O}$ solo na área experimental foi classificado como Cambissolo eutrófico, textura média, com a seguinte composição química na camada de 0 a $30 \mathrm{~cm}: \mathrm{pH}\left(\mathrm{H}_{2} \mathrm{O}\right)=6,5$; M.O.= 1,6 $\mathrm{g} \mathrm{dm}^{-3} ; \mathrm{P}=6,0 \mathrm{mg} \mathrm{dm}^{-3} ; \mathrm{K}^{+}=60 \mathrm{mg} \mathrm{dm}^{-3} ; \mathrm{Ca}^{+2}=$ $3,8 \mathrm{cmol}_{\mathrm{c}} \mathrm{dm}^{-3} ; \mathrm{Mg}^{+2}=1,0 \mathrm{cmol}_{\mathrm{c}} \mathrm{dm}^{-3} ; \mathrm{Al}^{+3}=0,1$ $\mathrm{cmol}_{\mathrm{c}} \mathrm{dm}^{-3} ; \mathrm{H}+\mathrm{Al}=4,0 \mathrm{cmol}_{\mathrm{c}} \mathrm{dm}^{-3}$ e $\mathrm{V}=55 \%$. A acidez foi corrigida seguindo recomendações da CFSEMG (1999). A adubação de plantio consistiu em $100 \mathrm{~kg} \mathrm{ha}^{-1}$ de $\mathrm{P}_{2} \mathrm{O}_{5}$, cuja fonte foi superfosfato simples, sendo aplicado todo o fósforo no fundo do sulco. A adubação total consistiu em $50 \mathrm{~kg} \mathrm{ha}^{-1} \mathrm{ano}^{-1}$ de $\mathrm{P}_{2} \mathrm{O}_{5}, 150 \mathrm{~kg} \mathrm{ha}^{-1}$ ano $^{-1}$ de $\mathrm{K}_{2} \mathrm{O}$ e $300 \mathrm{~kg} \mathrm{ha}^{-1}$ ano $^{-1}$ de $\mathrm{N}$, tendo como fontes o superfosfato simples, o cloreto de potássio e a uréia, respectivamente, sendo aplicado todo o fósforo em cobertura a cada ano. O cloreto de potássio e a uréia foram aplicados em cobertura, parcelada em 6 vezes ao ano, até o final da condução do experimento.

A distribuição granulométrica e os resultados das análises físico-hídricas do solo foram os seguintes:

As parcelas experimentais tinham $6 \mathrm{~m}$ de largura e $18 \mathrm{~m}$ de comprimento. As parcelas foram subdivididas em seis partes iguais, resultando em subparcelas de 6 × $3 \mathrm{~m}\left(18 \mathrm{~m}^{2}\right)$. As lâminas de água foram originadas das diferentes distribuições de água, na direção perpendicular à tubulação com os aspersores. Para isso, foi utilizado o sistema de irrigação por aspersão com distribuição dos aspersores em linha (Line Source Sprinkler System), conforme Hanks et al. (1976). As distâncias entre as linhas dos aspersores foram de 3-6, 9-12 e 15-18 metros, para os tramentos de lâmina de irrigação de 100, 45 e $0 \%$, respectivamente. A lâmina de irrigação de referência (100\%) foi determinada por meio do monitoramento do potencial de água no solo, feita por tensiômetro digital, instalado a 15 e $45 \mathrm{~cm}$ de profundidade. As irrigações foram efetuadas quando os tensiômetros instalados a 15 $\mathrm{cm}$ registraram valores de potencial matricial em torno de $-60 \mathrm{kPa}$. A lâmina de irrigação aplicada foi medida com pluviômetros instalados em cada subparcela experimental e calculada por meio da equação 1 .

$$
\mathrm{L}=\frac{(\mathrm{CC}-\theta)}{10} \mathrm{Ds} \mathrm{Z} \frac{1}{\mathrm{Ea}}
$$

em que,

$\mathrm{L}=$ lâmina total necessária $(\mathrm{mm})$;

$\mathrm{CC}=$ capacidade de campo $\left(\mathrm{g} \mathrm{g}^{-1}\right)$;

$\theta=$ conteúdo de água do solo, correspondente ao potencial matricial de $-60 \mathrm{kPa}\left(\mathrm{g} \mathrm{g}^{-1}\right)$;

Ds $=$ densidade do solo $\left(\mathrm{Mg} \mathrm{m}^{-3}\right)$;

$\mathrm{Z}$ = profundidade efetiva do sistema radicular (cm); e

Ea = eficiência de aplicação de água (decimal).
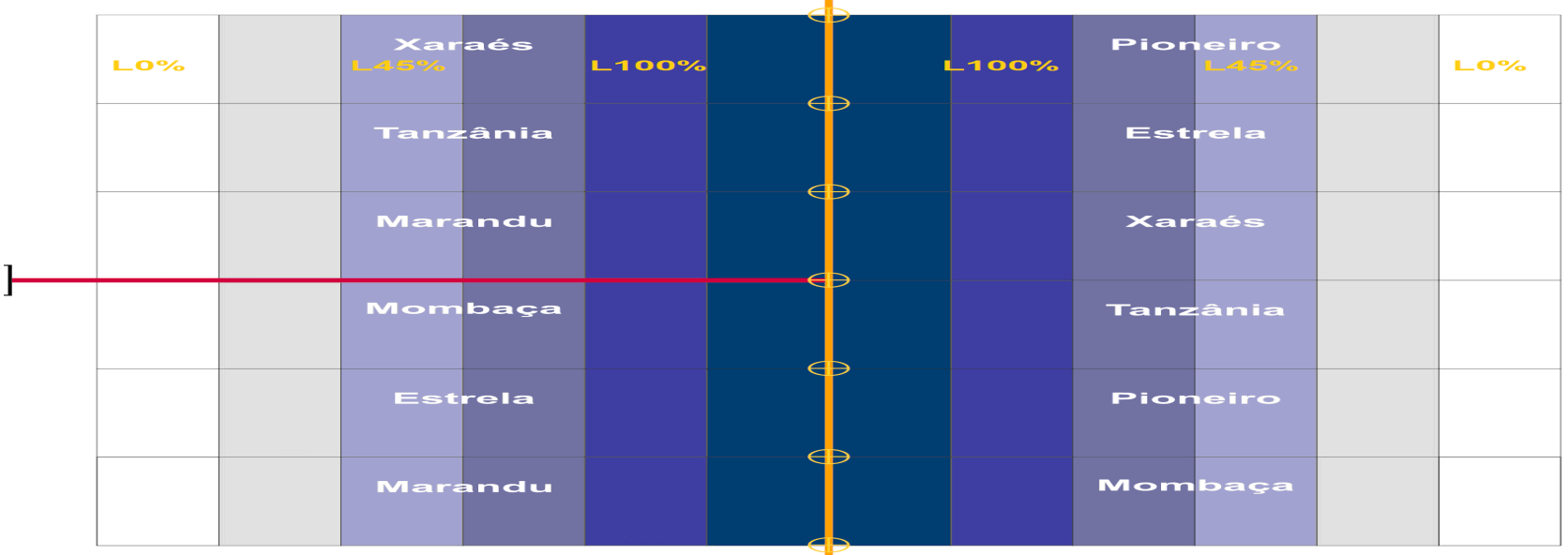

Figura 1. Esquema de distribuição das parcelas na área experimental. 
Simultaneamente ao monitoramento da umidade do solo, via tensiometria, foram coletados dados meteorológicos diários, a partir de uma estação meteorológica automática, instalada dentro da área experimental.

O experimento foi realizado sob manejo de pastejo. Aos 45 dias após o corte de uniformização, foi realizado o primeiro pastejo monitorado nas subparcelas, de maneira que o resíduo remanescente pós-pastejo apresentasse em torno de $15 \%$ de folhas verdes remanescentes, conforme Aroeira et al. (1999). O mesmo procedimento foi adotado nas demais coletas e nos pastejos seguintes, porém, com intervalos de 30 dias até o término do experimento. Os animais foram utilizados apenas como "ferramenta de corte", após a amostragem de cada capim, de maneira que a forragem disponível fosse consumida.

Após dois anos de experimento, o estudo de distribuição do sistema radicular foi realizado por meio de amostragens a cada $10 \mathrm{~cm}$ de profundidade, ao longo do perfil do solo explorado pelas raízes. O ponto de amostragem na seção transversal foi entre as touceiras de capim. A amostragem do material de solo e raízes foi feita com um trado tipo Uhland, com anel de $10 \mathrm{~cm}$ de diâmetro e $10 \mathrm{~cm}$ de altura. As raízes contidas nas amostras foram submetidas a uma rigorosa e cuidadosa limpeza, com água corrente e peneiras, sendo posteriormente colocadas em saco de papel, identificados e levadas à estufa com circulação forçada de ar a $65^{\circ} \mathrm{C}$, durante $72 \mathrm{~h}$. Em seguida foi feita a pesagem em balança de precisão $\left(10^{-5} \mathrm{~g}\right)$. A massa de raízes foi dividida pelo volume da amostra, obtendo-se, dessa forma, a densidade de raiz em cada amostragem. A densidade de raiz foi obtida pela densidade média de todas as amostras. A profundidade efetiva do sistema radicular foi definida conforme a profundidade onde se concentravam $80 \%$ da massa das raízes.

Os dados foram submetidos às análises de variância e de regressão. A comparação de médias foi realizada, usando-se o teste de Tukey a 5\% de probabilidade. Para execução das análises estatísticas, foi utilizado o programa estatístico SAEG 9.0.

\section{RESULTADOS E DISCUSSÃO}

Os valores médios mensais dos elementos meteorológicos, obtidos durante o período estudado, são apresentados nas Figuras 2, 3 e 4.

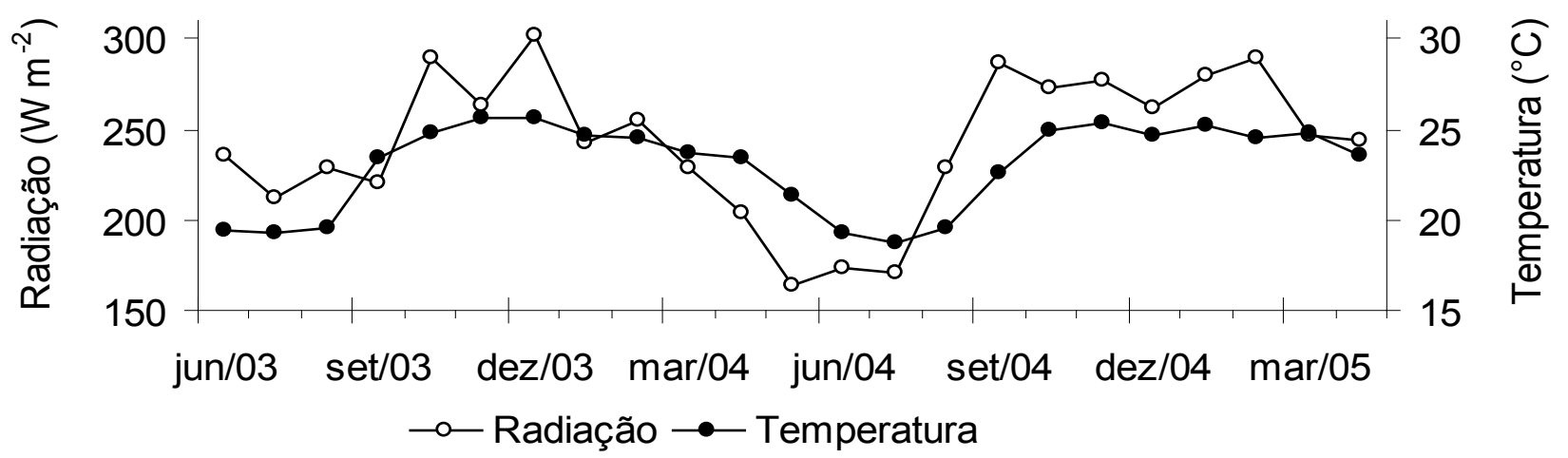

Figura 2. Variação mensal da radiação solar média $\left(\mathrm{W} \mathrm{m}^{-2}\right)$ e da temperatura média $\left({ }^{\circ} \mathrm{C}\right)$, no período de junho de 2003 a abril de 2005.

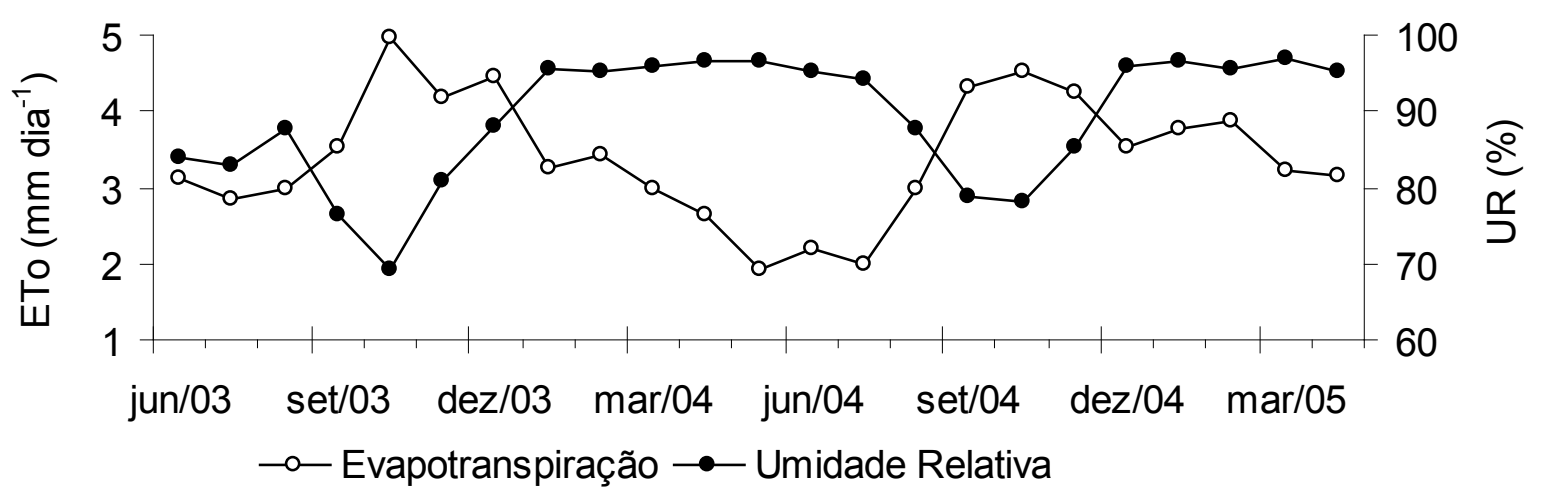

Figura 3. Variação média diária da evapotranspiração de referência $\left(\mathrm{mm} \mathrm{dia}^{-1}\right)$ e mensal da umidade relativa (\%), no período de junho de 2003 a abril de 2005. 


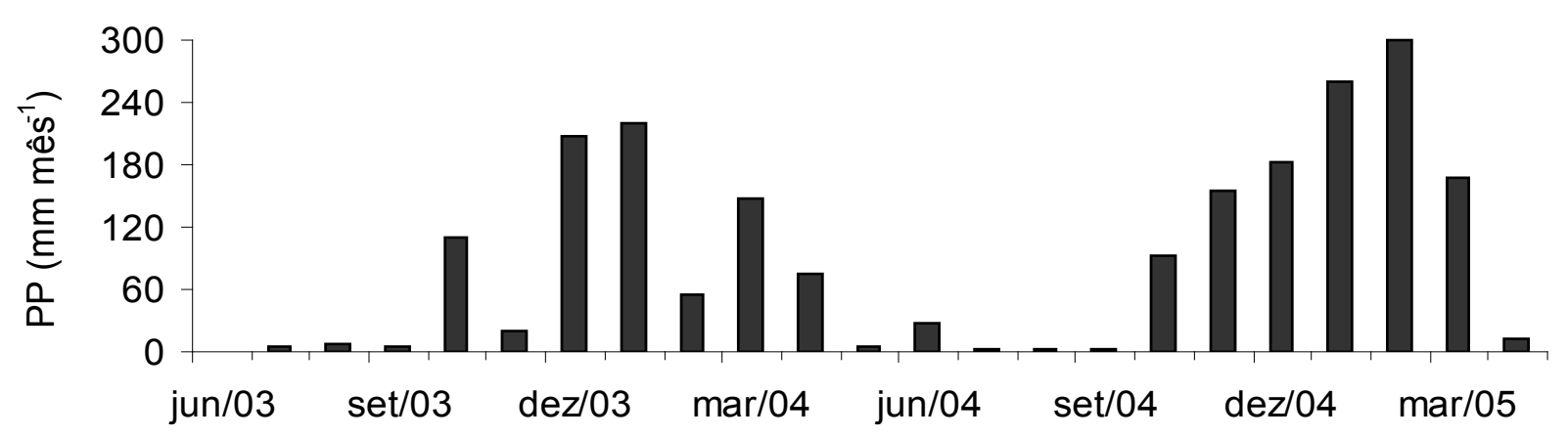

Figura 4. Variação média mensal da precipitação pluviométrica (mm mês ${ }^{-1}$ ), no período de junho de 2003 a abril de 2005.

Quadro 1. Valores médios de densidade de raiz $\left(\mathrm{g} \mathrm{dm}^{-3}\right)$, sob condições de pastejo, das respectivas combinações de lâminas de irrigação e capins

\begin{tabular}{ccccc}
\hline Capim & $0 \%(0 \mathrm{~mm})$ & $45 \%(252 \mathrm{~mm})$ & $100 \%(560 \mathrm{~mm})$ & Média \\
\hline Xaraés & $0,31 \mathrm{Ab}$ & $1,81 \mathrm{Aa}$ & $1,81 \mathrm{Aa}$ & 1,31 \\
Mombaça & $0,48 \mathrm{Aa}$ & $0,65 \mathrm{Ba}$ & $0,73 \mathrm{Bca}$ & 0,62 \\
Tanzânia & $0,91 \mathrm{Aa}$ & $0,44 \mathrm{Ba}$ & $0,44 \mathrm{Ca}$ & 0,60 \\
Pioneiro & $0,38 \mathrm{Aa}$ & $0,59 \mathrm{Ba}$ & $0,46 \mathrm{Ca}$ & 0,47 \\
Marandu & $0,76 \mathrm{Ab}$ & $1,66 \mathrm{Aa}$ & $1,22 \mathrm{Abab}$ & 1,21 \\
Estrela & $0,32 \mathrm{Aa}$ & $0,73 \mathrm{Ba}$ & $0,98 \mathrm{Bca}$ & 0,68 \\
\hline Média & 0,53 & 0,98 & 0,94 & 0,81 \\
\hline
\end{tabular}

Médias seguidas de letras minúsculas diferentes na linha e seguidas de letras maiúsculas diferentes na coluna diferem estatisticamente, pelo teste de Tukey $(p<0,05)$.

Os valores médios de radiação solar apresentaram grandes oscilações durante todo $\mathrm{o}$ período experimental e variaram de 738 a $1103 \mathrm{~W} \mathrm{~m}^{-2}$, nos períodos seco (entre abril e setembro) e chuvoso (entre outubro e março), respectivamente. Esse comportamento influenciou os valores de temperatura e, consequentemente, os de evapotranspiração de referência (ETo). Os valores médios de temperatura durante o experimento variaram de 18,7 a $25,6{ }^{\circ} \mathrm{C}$, sendo máximos entre os meses de outubro e março e mínimos entre os meses de abril e setembro. Os valores médios mensais de ETo durante o estudo variaram de 1,92 a $4,98 \mathrm{~mm} \mathrm{dia}^{-1}$, sendo mínimos em maio de 2004 e máximos em outubro de 2003. Os valores médios de umidade relativa variaram entre 69 a $97 \%$. O comportamento da umidade relativa foi o oposto da radiação solar e da temperatura, observando-se valores máximos entre os meses de dezembro e maio e mínimos entre os meses de junho e novembro. A precipitação pluvial foi praticamente nula entre os meses de abril e setembro (período outono/inverno), salvo 76 e $28 \mathrm{~mm}$ precipitados em abril e junho de 2004, respectivamente. No período de outubro de 2003 a março de 2004 (período primavera/verão), a precipitação pluvial foi de $763 \mathrm{~mm}$ e, de outubro de 2004 a março de 2005, de $1158 \mathrm{~mm}$.
No Quadro 1 estão apresentados os valores médios de densidade de raiz (DR) dos capins e das lâminas de irrigação estudadas. Observou-se que, dentro dos tratamentos não irrigados $(0 \%$ da referência), os capins não diferiram $(p>0,05)$ em relação a essa característica. Na lâmina de irrigação de $45 \%$ da referência $(252 \mathrm{~mm})$, verificou-se que os capins Xaraés e Marandu alcançaram maiores $(p<0,05)$ médias de DR em relação aos outros capins. Na lâmina de irrigação de $100 \%$ da referência $(560 \mathrm{~mm})$ o capim-xaraés foi o que apresentou maior $(p<0,05)$ média de DR, não diferindo do Marandu, que por sua vez não diferiu $(p>0,05)$ dos capins Mombaça e Estrela. Nessa mesma lâmina de irrigação (560 $\mathrm{mm}$ ), os capins Tanzânia e Pioneiro exibiram os menores $(p<0,05)$ valores de DR. É válido ressaltar o desempenho dos capins Xaraés e Marandu quando irrigados, pois são importantes para a conservação e incremento de matéria orgânica do solo, por causa da alta produção de raízes.

Esses capins, porém, não possuem maior capacidade em absorver água e nutrientes, pois essa característica não aumenta em proporção ao aumento da DR. Enquanto novas raízes com alta capacidade de absorção estão sendo produzidas, raízes mais velhas se tornam menos permeáveis (KRAMER, 1983). 
Os valores de DR do capim-tanzânia estão próximos aos dos encontrados na literatura. Pagotto (2001), avaliando a DR do capim-tanzânia irrigado com 30 dias após o pastejo, no município de Piracicaba, SP, obteve valores de 0,$44 ; 0,71 ; \mathrm{e} 0,84 \mathrm{~g} \mathrm{dm}^{-3}$, nas estações primavera, verão e outono, respectivamente. Giacomini et al. (2005), ao avaliarem dois capins utilizando duas doses de nitrogênio, no município de Nova Odessa, SP, observaram valores de DR de 1,6 e 1,2 $\mathrm{g} \mathrm{dm}^{-3}$, com a dose de $150 \mathrm{~kg} \mathrm{ha}^{-1} \mathrm{ano}^{-1}$, e 1,8 e $1,1 \mathrm{~g} \mathrm{dm}^{-3}$, com a dose de $300 \mathrm{~kg} \mathrm{ha}^{-1} \mathrm{ano}^{-1}$, nos capins Tanzânia e Aruana, respectivamente. A DR do capim-mombaça encontrada neste trabalho foi menor do que a encontrada por Gomide et al. (2003). Esses autores, trabalhando no município de Viçosa, MG, apresentaram valores médios de DR de 0,2 e $1,2 \mathrm{~g} \mathrm{dm}^{-3}$, respectivamente, 16 e 37 dias após a emergência.

$\mathrm{O}$ efeito das lâminas de irrigação na DR não foi verificado $(p>0,05)$ nos capins Mombaça, Tanzânia, Pioneiro e Estrela. Cunha et al. (2007), avaliando o capim-tanzânia com os mesmos níveis de irrigação no município de Viçosa, MG, também não observaram efeito das lâminas de irrigação na DR do capim. No capim-xaraés, as lâminas de irrigação de 45\% (252 $\mathrm{mm})$ e $100 \%$ da referência $(560 \mathrm{~mm})$ não diferiram entre si $(p>0,05)$ e apresentaram maior $(p<0,05) \mathrm{DR}$ em relação ao tratamento nãoirrigado. No capim-marandu, observou-se que apenas a lâmina de irrigação de $45 \%$ de referência $(252 \mathrm{~mm})$ proporcionou maior $(p<0,05) \mathrm{DR}$ que o tratamento não irrigado.

Além de a DR ser dependente do capim e da lâmina de irrigação, como observado nesta pesquisa, esse fator também é influenciado pelo manejo e pela temperatura, entre outros. DeLucia et al. (1992) relataram que temperaturas muito baixas são limitantes ao crescimento do sistema radicular das forrageiras. Scheffer-basso et al. (2002) observaram, no capim Bromus auleticus, que a quantidade de raiz produzida diminuiu em 53 e $55 \%$, à medida que cortes mais frequentes e mais baixos foram efetuados, respectivamente. Shaffer et al. (1994), trabalhando com três capins nos EUA, verificaram que, dos 20 aos 52 dias após o corte, a DR aumentou cerca de 365, 591 e 304\%, em Bromus willdenowii Kunth., Festuca arundinacea Schreb. e Bromus inermis Leyss, respectivamente. Esses autores também observaram redução na $\mathrm{DR}$, da profundidade de 10 para $20 \mathrm{~cm}$, de 40, 58 e 66\% para Bromus willdenowii Kunth., Festuca arundinacea Schreb. e Bromus inermis Leyss, respectivamente. Cecato et al. (2001), trabalhando com peso de raízes em pastagem de Coastcross- 1 , observaram que a produção de matéria seca de raízes aumentou à medida que se elevaram os níveis de resíduo de matéria seca aérea. Após um corte no capim, a quantidade de raiz diminui, pois há um declínio na produção de forragem elaborado para ela. Dependendo da quantidade de resíduo deixado, há menor declínio ou não do crescimento do sistema radicular.

Nos dados de profundidade efetiva (PE) do sistema radicular, não foi verificado nenhum efeito $(p>0,05)$. No Quadro 2 estão apresentados os valores médios de $\mathrm{PE}$ dos diferentes capins e lâminas de irrigação. Apesar de não ter sido verificado efeito estatístico, o capimmarandu merece destaque, por ter apresentado valor médio de PE do sistema radicular maior em todas as lâminas de irrigação estudadas, em comparação com os outros capins. Esse valor foi próximo ao de $70 \mathrm{~cm}$ encontrado por Volaire et al. (1998), na região sul da França, em Lolium perenne L. No entanto, os capins Xaraés e Mombaça apresentaram menores valores de PE, evidenciando que, apesar de o capim-xaraés ter produzido maior peso de matéria seca de raízes (Quadro 1), estas ficaram concentradas nas primeiras camadas do solo. Essa característica é indesejável, pois, em longos períodos de veranicos, essas forrageiras terão maior dificuldade de absorver água de camadas profundas e poderão sofrer, mais rapidamente, o estresse hídrico. Outro problema que a PE do sistema radicular menor ou superficial traz é a redução do raio de ação da planta para obtenção de nutrientes do solo. Para haver compensação disso, a planta exige maior concentração de nutrientes

Quadro 2. Valores médios de profundidade efetiva do sistema radicular $(\mathrm{cm})$, sob condições de pastejo, das respectivas combinações de lâminas de irrigação e capins

\begin{tabular}{ccccc}
\hline Capim & $0 \%(0 \mathrm{~mm})$ & $45 \%(252 \mathrm{~mm})$ & $100 \%(560 \mathrm{~mm})$ & Média \\
\hline Xaraés & 33,71 & 46,37 & 44,54 & 41,54 \\
Mombaça & 45,18 & 25,00 & 43,58 & 37,92 \\
Tanzânia & 56,54 & 57,99 & 66,05 & 60,20 \\
Pioneiro & 70,58 & 35,06 & 52,77 & 52,80 \\
Marandu & 72,10 & 69,51 & 66,66 & 69,42 \\
Estrela & 45,61 & 51,05 & 60,07 & 52,24 \\
\hline Média & 53,95 & 47,50 & 55,61 & 52,35 \\
\hline
\end{tabular}


num menor volume de solo. Gregory (1994) demonstrou esse fato ao evidenciar a importância do comprimento de raízes para taxas máximas de absorção do amônio em solução, quando foram exigidos 100 e $5 \mathrm{~cm}$ de raízes para cada $\mathrm{cm}^{3}$ de solo, quando a disponibilidade desse íon no solo foi baixa e alta, respectivamente.

$\mathrm{O}$ valor médio da $\mathrm{PE}$ do sistema radicular do capimtanzânia foi maior do que os relatados na literatura. Cunha et al. (2007), no município de Viçosa, MG, e DelgadoRojas et al. (2004) em Piracicaba, SP, encontraram valores médios de 50 e $38 \mathrm{~cm}$, respectivamente. Howell (1999) relatou que alguns capins das espécies Saccharum spontaneum, Thysanolaena maxima e Cymbopogon microtheca atingem uma PE do sistema radicular entre 50 e $100 \mathrm{~cm}$, já as das espécies Cynodon dactylon e Pennisetum clandestinum podem chegar a valores acima de $100 \mathrm{~cm}$. Kafle (2005) relatou grande variabilidade da PE do sistema radicular das pastagens, citando valores entre 14-54, 15-27 e 70-95 cm em capins Napier, Molasses e Amliso, respectivamente, e de 24-130 em Stylosanthes.

Quanto ao efeito proporcionado pela lâmina de irrigação, os resultados deste trabalho diferem de alguns encontrados na literatura. Cunha et al. (2007) observaram que, quanto maior a lâmina de irrigação, maior a PE do sistema radicular do capim-tanzânia. Eles relataram que o aumento da lâmina de irrigação fez que maior quantidade de água atingisse regiões mais profundas, permitindo ao sistema radicular atingir maior profundidade.

Segundo Jordan et al. (2003), um fator dentro da irrigação que afeta fortemente o comportamento do sistema radicular é o turno de rega. Quando as aplicações das irrigações são mais frequentes, menor é a PE do sistema radicular. Cunha et al. (2007) constataram esse efeito avaliando o capim-tanzânia. Eles encontraram valores de PE do sistema radicular de 48, 50 e $52 \mathrm{~cm}$, nos turnos de rega de um, quatro e sete dias, respectivamente.

Na Figura 5, estão apresentados os valores médios da percentagem de raiz acumulada ao longo do perfil do solo para os seis capins irrigados com a lâmina de referência $(100 \%)$. Analisando essa figura, observa-se que entre as profundidades de 0 a $70 \mathrm{~cm}$ continham mais de $80 \%$ do total das raízes dos capins.

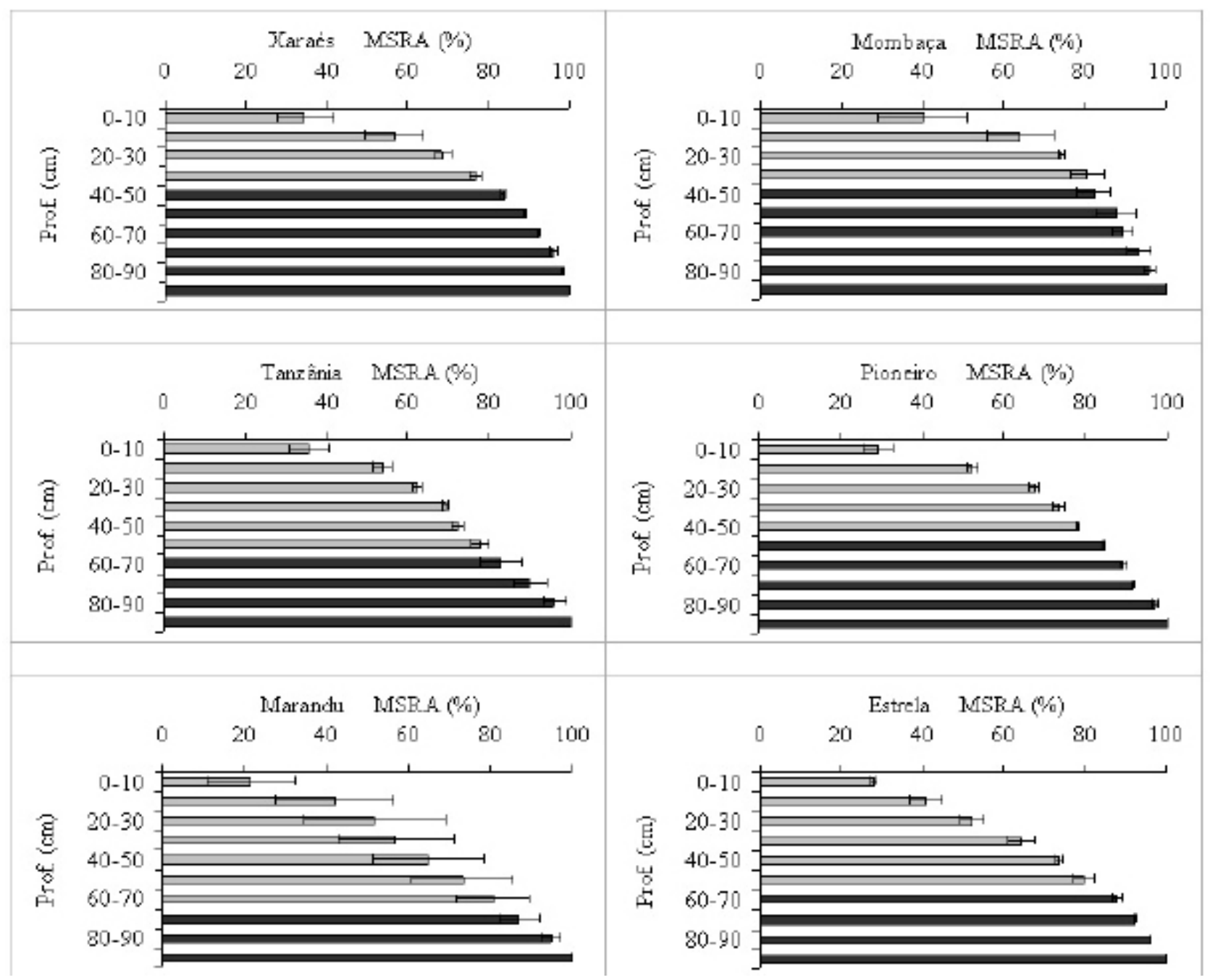

Figura 5. Matéria seca de raiz acumulada (MSRA) ao longo do perfil do solo na lâmina de irrigação de referência (100\%), sob condições de pastejo, para seis capin. 
CONCLUSÕES

Diante dos resultados, concluiu-se que:

- O capim-marandu destaca-se por apresentar maior profundidade efetiva do sistema radicular e juntamente com o capim-xaraés apresenta maior densidade de raiz apenas quando irrigados; e

- As lâminas de irrigação não influenciam a profundidade efetiva e aumenta a densidade radicular apenas nos capins Xaraés e Mombaça.

\section{REFERÊNCIAS BIBLIOGRÁFICAS}

AROEIRA, L.J.M.; LOPES, F.C.F.; DERESZ, F.; VERNEQUE, R.S.; DAYRELL, M.S.; MATOS, L. L.; MALDONADO VASQUEZ, H.; VITTORI, A. Pasture availability and dry matter intake of lactating crossbred cows grazing elephant grass (Pennisetum purpureum, Schum). Animal Feed Science and Technology, Amsterdam, v.78, n.3, p.313-324, 1999.

CECATO, U.; CANO, C.C.P.; BORTOLO, M.; HERLING, V.R.; CANTO, M.W.; CASTRO, C.R.C. Teores de carboidratos não-estruturais, nitrogênio total e peso de raízes em Coastacross-1 (Cynodon dactylon (L.) Pers) pastejado por ovinos. Revista Brasileira de Zootecnia, Viçosa, v.30, n.3, p.644650, 2001.

CFSEMG - Comissão de Fertilidade do Solo do Estado de Minas Gerais. Recomendações para o uso de corretivos e fertilizantes em Minas Gerais: $\mathbf{5}^{\text {a }}$ aproximação. 20. ed. Viçosa: Imprensa Universitária, 1999. 359p.

CORSI, M.; NASCIMENTO Jr., D. Princípios de fisiologia e morfologia de plantas forrageiras aplicadas no manejo das pastagens. In: PEIXOTO, A.M.; MOURA, J.C.; FARIA, V.P. (Eds.). Pastagens: Fundamentos da exploração racional. Piracicaba: FEALQ, 1994. p.15-48.

CUNHA, F.F.; SOARES, A.A.; SEDIYAMA, G.C.; MANTOVANI, E.C.; PEREIRA, O.G.; ABREU, F. V.S.; SOUZA, D.O. Avaliação do sistema radicular do capim-tanzânia submetido a diferentes níveis de irrigação e turnos de rega. Revista Engenharia na Agricultura, Viçosa, v. 15, n. 3, p. 200-211, 2007.
DELGADO-ROJAS, J.S.; NOVAES, M.; LOURENÇO, L. F.; COELHO, R. D. Evapotranspiração máxima do capim-tanzânia (Panicum maximum J.) em pastejo rotacionado, baseada na evaporação do tanque "classe A" e no índice de área foliar. Engenharia Agrícola, Jaboticabal, v. 24, n. 1, p. 226-234, 2004.

DeLUCIA, E.H.; HECKATHORN, S.A.; DAY, T.A. Effects of soil temperature on growth, biomass allocation and resource acquisition of Andropogon gerardii Vitman. New Phytologist, New York, v. 120, n.4, p.543-549, 1992.

DOORENBOS, J.; PRUITT, W.O. Crop water requirements. Rome: FAO, 1977. 144p.

EMBRAPA - Empresa Brasileira de Pesquisa Agropecuária. Manual de métodos de análise de solo. 2.ed. Rio de Janeiro: EMBRAPA-CNPS, 1997. $212 \mathrm{p}$.

FERNANDES, A.M.; QUEIROZ, A.C.; PEREIRA, J.C.; LANA, R.P.; BARBOSA, M.H.P.; FONSECA, D.M.; DETMANN, E.; CABRAL, L.S.; PEREIRA, E.S.; VITTORI, A. Composição químicobromatológica de variedades de cana-de-açúcar (Saccharum spp L.) com diferentes ciclos de produção (precoce e intermediário) em três idades de corte. Revista Brasileira de Zootecnia, Viçosa, v.32, n.4, p.977-985, 2003.

GIACOMINI, A.A.; MATTOS, W.T.; MATTOS, H.B.; WERNER, J.C.; CUNHA, E.A.; CARVALHO, D.D. Crescimento de raízes dos capins Aruana e Tanzânia submetidos a duas doses de nitrogênio. Revista Brasileira de Zootecnia, Viçosa, v.34, n.4, p.1109-1120, 2005.

GOMIDE, C.A. M.; GOMIDE, J. A.; ALEXANDRINO, E. Índices morfogênicos e de crescimento durante o estabelecimento e a rebrotação do capim-mombaça (Panicum maximum Jacq.) Revista Brasileira de Zootecnia, Viçosa, v.32, n.4, p.795-803, 2003.

GREGORY, P. J. Root growth and activity. In: BOOTE, K. J.; BENNETT, J. M.; SINCLAIR, T. R.; PAULSEN, G. M. (Eds.). Physiology and determination of crop yield, Madison: ASA/CSSA/ SSSA, 1994. p. 65-93. 
HANKS, R.J.; KELLER, J.; RASMUSSEN, V.P.; WILSON, G.D. Line source sprinkler for continuous variable irrigation crop production studies. Soil Science of American Journal, Madison, v. 40, n. 3, p. 426-429, 1976.

HOWELL, J. Roadside bio-engineering. Kathmandu: Department of Roads, 1999. 216p.

HUNT, H.W.; MORGAN, J.A.; READ, J.J. Simulating growth and root-shoot partitioning in prairie grasses under elevated atmospheric $\mathrm{CO}_{2}$ and water stress. Annals of Botany, London, v.81, n.4, p.489-501, 1998.

JORDAN, J.E.; WHITE, R.H.; VIETOR, D.M.; HALE, T.C.; THOMAS, J.C.; ENGELKE, M.C. Effect of irrigation frequency on turf quality, shoot density, and root lenght density of five bentgrass cultivars. Crop Science, Madison, v.43, n.1, p.282287, 2003.

KAFLE, G. Effectiveness of root and foliage systems of grasses used in soil conservation. Pokhara: Institute of Forestry Pokhara Campus, 2005. 45p. (Thesis Degree of Bachelor).

KRAMER, P. J. Water relations of plant. Orlando: Academic Press, 1983.489 p.

PAGOTTO, D.S. Comportamento do sistema radicular do capim-tanzânia (Panicum maximum, Jacq.) sob irrigação e submetido a diferentes intensidades de pastejo. 2001. 51f. Dissertação (Mestrado)-ESALQ, Piracicaba. 2001.

RASSINI, J.R. Manejo de água de irrigação para alfafa (Medicago sativa L.). Revista Brasileira de Zootecnia, Viçosa, v.30, n.6, p. 1681-1688, 2001.

RICHARDS, L.A. Methods of measuring soil moisture tension. Soil Science of American Journal, Baltimore, v.68, n.1, p.95-112, 1949.

SCHEFFER-BASSO, S.M.; SOARES, G.C.; DALL' AGNOL, M. Efeito de freqüência e altura de corte em dois genótipos de Bromus auleticus trin. ex ness. Revista Brasileira de Agrociência, Pelotas, v. 8, n. 3, p.191-194, 2002.

SHAFFER, J.A.; JUNG, G.A.; NAREM, U.R. Root and shoot characteristics of prairie grass compared to tall fescue and smooth brome grass during establishment. New Zealand Journal of Agricultural Research, Wellington, v.37, n.2, p. 143-151, 1994.

VOLAIRE, F.; THOMAS, H.; LELIÈVE, F. Survival and recovery of perennial forage grasses under prolonged Mediterranean drought. New Phytology, Cambridge, v.140, n.3, p.439-449, 1998. 